Lecture Notes in Electrical Engineering 349

Mitsuo Gen

Kuinam J. Kim

Xiaoxia Huang

Yabe Hiroshi

Editors

Industrial Engineering,

Management Science

and Applications 2015 
Editors

Mitsuo Gen

Tokyo University of Science

Tokyo

Japan

Kuinam J. Kim

Department of Convergence Security

Inst. of Creative Advanced Tech.,

Sci. and Engg.

Kyonggi University

Suwon-si

Korea
Xiaoxia Huang

University of Science and Technology

Beijing

Beijing (USTB)

China

Yabe Hiroshi

Tokyo University of Science

Tokyo

Japan

ISSN 1876-1100 ISSN 1876-1119 (electronic)

Lecture Notes in Electrical Engineering

ISBN 978-3-662-47199-9

DOI 10.1007/978-3-662-47200-2

ISBN 978-3-662-47200-2 (eBook)

Library of Congress Control Number: 2015938793

Springer Heidelberg New York Dordrecht London

(C) Springer-Verlag Berlin Heidelberg 2015

This work is subject to copyright. All rights are reserved by the Publisher, whether the whole or part of the material is concerned, specifically the rights of translation, reprinting, reuse of illustrations, recitation, broadcasting, reproduction on microfilms or in any other physical way, and transmission or information storage and retrieval, electronic adaptation, computer software, or by similar or dissimilar methodology now known or hereafter developed.

The use of general descriptive names, registered names, trademarks, service marks, etc. in this publication does not imply, even in the absence of a specific statement, that such names are exempt from the relevant protective laws and regulations and therefore free for general use.

The publisher, the authors and the editors are safe to assume that the advice and information in this book are believed to be true and accurate at the date of publication. Neither the publisher nor the authors or the editors give a warranty, express or implied, with respect to the material contained herein or for any errors or omissions that may have been made.

Printed on acid-free paper

Springer-Verlag GmbH Berlin Heidelberg is part of Springer Science+Business Media (www.springer.com) 


\section{Organizing Committee}

\section{General Chairs}

Mitsuo Gen

Xiaoxia Huang

Kuinam J. Kim

Yabe Hiroshi

\section{Steering Committee}

Nikolai Joukov

Borko Furht

Bezalel Gavish

Kin Fun Li

\section{Publicity Chairs}

Dan (Dong-Seong) Kim

\section{Workshop Chairs}

Kuinam J. Kim

Donghwi Lee
Fuzzy Logic Systems Institute and Tokyo

University of Science, Japan

University of Science and Technology Beijing, China

Institute of Creative Advanced Technologies,

Science and Engineering, Republic of Korea Tokyo University of Science, Japan

Chair of IEEE CS STCOS, USA

Florida Atlantic University, USA

Southern Methodist University, USA

University of Victoria, Canada

University of Canterbury, New Zealand

Kyonggi University, Republic of Korea

University of Colorado, USA 


\section{Financial Chairs}

Kyoungho Choi

Institute of Creative Advanced Technologies, Science and Engineering, Republic of Korea

\section{Program Chairs}

Adel Hejaaji

Engineering Services Management Limited [ESM LTD] ESSEX, UK

\section{Organizers and Supporters}

Institute of Creative Advanced Technologies, Science and Engineering (iCatse) Chinese Management Science Society (CMSS)

Korean Industry Security Forum (KISF)

Korea Information Assurance Society (KIAS)

Kyonggi University

University of Science and Technology Beijing

Tokyo University of Science

River Publishers

\section{Program Committee}

Chil-Chyuan Kuo

Suksan Prombanpong

Ramayah Thurasamy

Siana Halim

Yves De Smet

Marco Aiello

Catalina Lucía Alberto

Llewellyn C.M. TANG

M. Birasnav

Enslin Johannes van Rooyen

Supachart Iamratanakul

Luciana Hazin Alencar

Jui-Sheng Chou

Shimpei Matsumoto

Ahm Shamsuzzoha

Minghai Jiao

Masaharu Tsujimoto
Ming Chi University of Technology, Taiwan

King Mongkut's University of Technology

Thonburi, Thailand

Universiti Sains Malaysia, Malaysia

Petra Christian University, Indonesia

Université Libre de Bruxelles, Belgium

University of Groningen, The Netherlands

Universidad Nacional de Córdoba, Argentina

University of Nottingham Ningbo China, China

New York Institute of Technology, USA

Tshwane University of Technology, South Africa

Kasetsart University, Thailand

Universidade Federal de Pernambuco, Brazil

National Taiwan University of Science and

Technology, Taiwan

Hiroshima Institute of Technology, Japan

University of Vaasa, Finland

Northeastern University, China

Tokyo Institute of Technology, Japan 
Ahm shamsuzzoha

Seren OZMEHMET TASAN

Yoshinobu Tamura

António Grilo

Fabrizio Maria Maggi

V. Cruz Machado

Md Mamun Habib

Kittisak Jermsittiparsert

Adel Hejaaji

Ulrich Reimer

Hardeep Singh

Fatemeh Almasi

Yiliu Liu

Ryo HARUNA

Ilias Santouridis

Purit Thanakijkasem

Chun-Cheng Lin

Michel ALDANONDO

Jinho Lee

Mojahid F. Saeed Osman

Wasawat Nakkiew

Somlak Wannarumon

KIELAROVA

Jaekyung Yang

Suprakash Gupta

Alejandro Escudero-Santana

RIKA AMPUH HADIGUNA

Andreas Dewald

Kit Fai Pun

Abdol S. SOOFI

El-Houssaine AGHEZZAF

Chompoonoot Kasemset

Ana Paula Ferreira Barroso

Virgínia Helena Arimateia

de Campos Machado

Antonio Ruiz Molina
Sultan Qaboos University, Oman

Dokuz Eylul University, Turkey

Yamaguchi University, Japan

Faculdade de Ciências e Tecnologia da

Universidade Nova de Lisboa, Portugal

University of Tartu, Estonia

Universidade Nova de Lisboa, Portugal

Universiti Utara Malaysia, Malaysia

Rangsit University, Thailand

Engineering Services Management Limited

[ESM LTD] ESSEX, UK

University of applied sciences St. Gallen,

Switzerland

Ferozepur College of Engg \& Technology, India

Amirkabir University of Technology

(Tehran polytechnic), Iran

Norwegian University of Science and Technology, Norway

Kanazawa Gakuin University, Japan

Technological Educational Institute (TEI) of

Thessaly, Greece

King Mongkut's University of Technology

Thonburi, Thailand

National Chiao Tung University, Taiwan

Toulouse University - Mines Albi -, France

Korea Naval Academy, Republic of Korea

King Fahd University of Petroleum and Minerals, Saudi Arabia

Advanced Manufacturing Technology

Research Center (AMTech), Chiang

Mai University, Thailand

Naresuan University, Thailand

Chonbuk National University, Republic of Korea

Indian Institute of Technology (B H U), India

Universidad de Sevilla, Spain

Andalas University, Indonesia

University of Erlangen, Germany

The University of the West Indies, West Indies

University of Wisconsin-Platteville, USA

Ghent University, Belgium

Chiang Mai University, Thailand

Universidade Nova de Lisboa, Portugal

Universidade Nova de Lisboa, Portugal

University of Malaga, Spain 


\section{Contents}

Regional Location Decision for Thai Garment Industry:

An AEC Perspective . . . . . . . . . . . . . . . . . . . . . . .

Walailak Atthirawong, Wariya Panprung

Key Performance Indicators for Sustainable Campus Assessment:

A Case of Andalas University

Elita Amrina, Febriza Imansuri

Minimum Partial Encryption for JPEG/JPEG2000 Medical Image

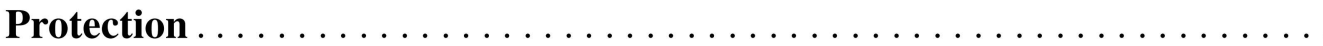

Seong Min Yoo, Jun Hoo Park, Jae Cheol Ryou

The Optimal Hedging Strategy for Commodity Processors

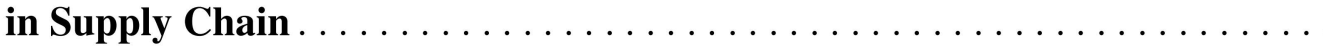

Ehsan Bolandifar, Zhong Chen

Application of MFCA and Dynamic Programming in Operations

Improvement: A Case Study

Atchara Songkham, Chompoonoot Kasemset

Value Analysis of Coco Board for Production Sustainability

Marianne B. Calayag

Effect of Temperature on the Colour and TSS Removal of Batik Dye Wastes in an Integrated Biological and Filtration Treatment System . . . . . .

N.A. Ramlee, M.N. Mohd Rodhi, S.F. Abdul Manaf, F. Hamzah,

A. Anuar, A. Datu Brandah

A Multi-agent Approach for Production Management

Ana Paula M. Tanajura, Valdir Leanderson C. Oliveira, Herman Lepikson

Design of Experiment for Predicting Residual Stresses in Gas Tungsten Arc Welding Process . . . . . . . . . . . . . . . . . . . . . . . . 
Hands-on Industrial Process Modelling Using the MATLAB System Identification Toolbox . . . . . . . . . . . . . . . . . . . . . . . .

Abubakar Sadiq Bappah

Model Based Design of Finger Exoskeleton for Post Stroke Rehabilitation Using a Slotted Link Cam with Lead Screw Mechanism . . . . . . . . . . . 95 Mohd Nor Azmi Bin Ab Patar, Takashi Komeda, Jamaluddin Mahmud, Cheng Yee Low

Quantile Estimation Using a Combination of Stratified Sampling and Control Variates.

Marvin K. Nakayama

A Simulation-Based Analysis for Inter Release Problem in Airport

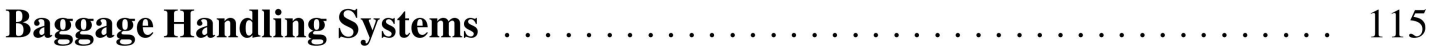
James T. Lin, Irene Liou, Chun-Chih Chiu

A New Two-Phase Approach for Petri Net Based Modeling

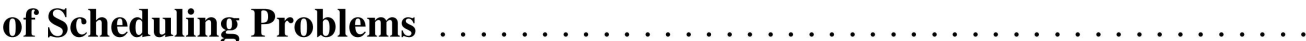

Simulation and Analysis of Impulse Faults in Power Transformer .

Kaveri Bhuyan, Saibal Chatterjee, Anwesa Yadav, Sarita Bansal,

Sanat Kumar Paul

The Online Study Design for Different Study Location Environment, Using ICT and Social Methodology Tool

Platt Pangthong, Phudinan Singkamfu

Telematics Technology Development Forecasting: The Patent Analysis and Technology Life Cycle Perspective

Shu-Hao Chang, Chin-Yuan Fan

Empirical Study of Collaborative Learning Knowledge Management System for Thai Students

Krittawaya Thongkoo, Chiraporn Thongkhu

Factors for Enterprise Resource Planning System Selection to Support

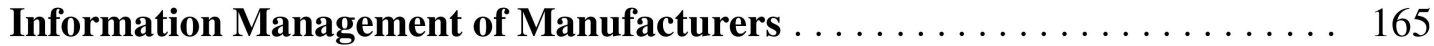
Porntida Kaewkamol

Low Level of Licensing Activities by Universities in Japan . . . . . . . . . . 173 Shigenori Hata, Kumiko Miyazaki

Analysing Industry Clustering to Develop Competitive Advantage

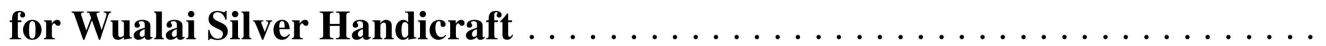


University-Industry Linkages (UILs) and Research Collaborations: Case of Thailand's National Research Universities (NRUs) . . . . . . . . . . . . 189 Naparat Siripitakchai, Kumiko Miyazaki

Factors Affecting the Use of Information Technology for Collaboration among Government, Educational and Tourism Small Business Sectors . . . . .

Kannika Daungcharone

How Managerial Capabilities of Entrepreneur Leverage Innovative Capability of SMEs: A Perspective of TIM

Qingrui Xu, Siyu Liu, Zhiyan Wu

Definition of Complex Hurst and Fractional Analysis for Stock

Market Fluctuation

Qing Zou, Yufan Hu, Jun Steed Huang

Water Cycle and Artificial Bee Colony Based Algorithms for Optimal Order Allocation Problem with Mixed Quantity Discount Scheme . . . . . . . 229 Chanikarn Praepanichawat, Charoenchai Khompatraporn, Chorkaew Jaturanonda, Chiranya Chotyakul

The Management of Assessment and Allocation of Marshalling Yards and Designation Their Catchment Areas $\ldots \ldots \ldots \ldots \ldots \ldots$

Juraj Camaj, Jana Lalinská, Jaroslav Masek

Improving Vehicle Routing Decision for Travel Agency in Chonburi,

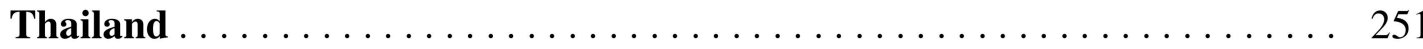

Tantikorn Pichpibul

Differential Evolution Algorithm for Storage Location Assignment Problem

Warisa Wisittipanich, Pongsakorn Meesuk

Master Production Scheduling for the Production Planning in the Pharmaceutical Industry .

Sivinee Wattitham, Tuanjai Somboonwiwat, Suksan Prombanpong

A Hybrid Genetic Algorithm for Simultaneous Scheduling of Machines

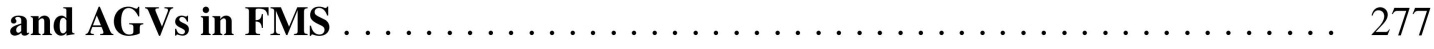
James T. Lin, Chun-Chih Chiu, Yu-Hsiang Chang, Hung-Ming Chen

Collaborative Agents Supporting Tactical Planning Activities - An

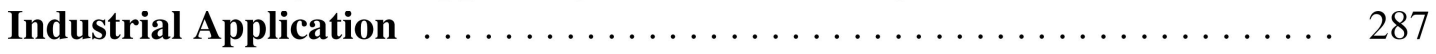
Ana Paula M. Tanajura, Pinar Öztürk, Herman Lepikson

Minimizing Makespan Using Node Based Coincidence Algorithm in the Permutation Flowshop Scheduling Problem 
An Inventory System of Packaging Materials: Case Study at PT. Djambi

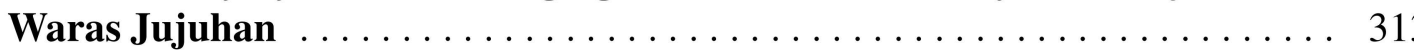

Nilda Tri Putri, Jonrinaldi, Y.R. Risa Noviani

A Pattern In Formgiving Design: Giving Priority To a Principle Solution

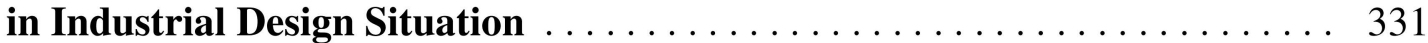

Rusmadiah Anwar, Shahriman Zainal Abidin, Oskar Hasdinor Hassan

Simulation of Logistic Operations .

Jana Lalinská, Kendra Martin, Čamaj Juraj

Contracting Decisions in Project Management - An Outline of the Dedicated Decision Support System .

Tomasz Błaszczyk, Pawet Błaszczyk

Factory Logistics Improvement Projects: Case Northern Thailand

Sakgasem Ramingwong, Apichat Sopadang,

Korrakot Yaibuathet Tippayawong

Enhancing Project Funding Decision Quality $\ldots \ldots \ldots \ldots \ldots \ldots \ldots \ldots$

Ofer Zwikael, Ying-Yi Chih

Software Project Team Selection Based on Enterprise Social Networks . . . . 375 Panos Fitsilis, Vassilios Gerogiannis, Leonidas Anthopoulos

Study on the Agriculture Information Cloud Architecture and Application .

Peng Qing, Ming Ye, Guangyuan Liu

Enhanced Value Stream Mapping: Potentials and Feasibility of IT Support through Manufacturing Execution Systems

Markus Philipp Roessler, Ina Kleeberg, Moritz Kreder, Joachim Metternich, Klaus Schuetzer

Automatic Oil Palm Detection and Identification from Multi-scale Clustering and Normalized Cross Correlation . . . . . . . . . . . . . . 403 Teerawut Wong-in, Tonphong Kaewkongka, Nagul Cooharojananone, Rajalida Lipikorn

A Comparison Approach for Accuracy Feature of Requirements Prioritization Models Jenjira Jaimunk, Pradorn Sureephong

A Novel Approach on Operation and Maintenance Guideline Using Semantic Processing and Clustering Ki Hoon Jang, Gyeong-June Hahm, Heejung Lee, Hyo-Won Suh 
Rutting Load Equivalency Factors of Heavy Vehicles Operating in the Sothern Part of Malaysian Peninsula . . . . . . . . . . . . . . . . . . . . . 429 Osama Mahmoud Yassenn, Intan Rohani Endut, Mohamed Ahmed Hafez,

Siti Zaharah Ishak

Enhancing Virtual Manipulatives for After-School Tutoring in the Subtraction Unit

Wen-Chung Shih

Implementing an Information System Development Simulation in an Industrial Engineering Class: A Case Study

Sakgasit Ramingwong, Lachana Ramingwong

Exploring the ISO 14001 Environmental Management System (EMS) towards SMEs Organizational Performance: Case Study of Southern Malaysia Furniture Manufacturers $\ldots \ldots \ldots \ldots \ldots \ldots \ldots \ldots \ldots \ldots \ldots \ldots \ldots$

A.H. Nor Aziati, Ng Seow Chian, Abdul Talib Bon, Y. Ngadiman, M.F. Ahmad

Happy Workers Work Happy? The Perspective of Frontline Service Workers

Wan-Jung Hsiao

Analyzing Cargo Loss Severity of Electronics Products

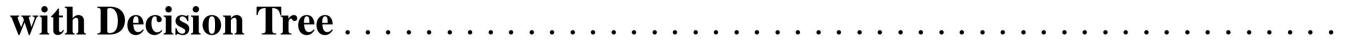

Mu-Chen Chen, Pei-Ju Wu, Chih-Kai Tsau

A Comparison of Inventory Management between Decentralized and Centralized Distribution Networks with Backorder

Kanokwan Singha, Parthana Parthanadee, Jirachai Buddhakulsomsiri

A Study on Hong Kong Rice Supply Chain Risk Management with Value Chain Analysis

Anthony Lam, Tao Zhang, Kin Keung Lai

The Role of Product Development to Drive Product Success:

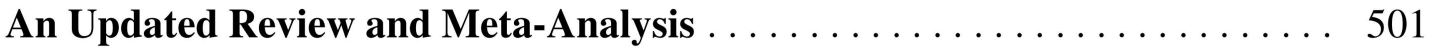

Yosephine Suharyanti, Subagyo, Nur Aini Masruroh, Indra Bastian

Management Practices of Thai Silk Product . . . . . . . . . . . . . . . 511

Kanogkan Leerojanaprapa, Walailak Atthirawong

Fuzzy Multi-objective Supplier Selection Problem:

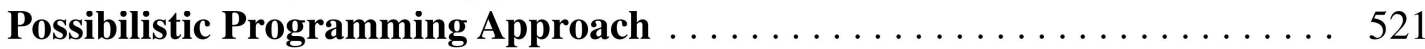

Dicky Fatrias, Ahmad Syafruddin Indrapriyatna, Difana Meilani

Value Adding and Improving Factors of Thai Long Steel Supply Chain for ASEAN Economic Community .

Apinun Chedchoosuwan, Tuanjai Somboonwiwat,

Charoenchai Khompatraporn 
Analysis of Causal Competitive Factors of Thai Iron and Steel Supply Chain by DEMATEL Method

Supattra Rattanavijit, Tuanjai Somboonwiwat, Charoenchai Khompatraporn

Combining Balanced Scorecard and Data Envelopment Analysis to Design Performance Measurement for Supply Chain Actor and Regulator: A Case Study in Innovative Product in Indonesia

Elisa kusrini, Subagyo, Nur Aini Masruroh

A Study of Consumers' Post Consumption Behaviour for Mobile Phone in Indonesia

Siti Mahsanah Budijati, Subagyo, Muhammad Arif Wibisono,

Nur Aini Masruroh

Green Supply Chain Assessment to Operations Improvement for Can Packaging Industry

Tuanjai Somboonwiwat, Tuangyot Supeekit, Patiyut Punta

Selection of Digital Marketing Channels: Application of Modern Portfolio Theory

Tomás Frausto-da-Silva, António Grilo, Virgílio Cruz-Machado

The Effect of Stockout Cause and Brand Equity on Consumer Preference in Online Retailing . . . . . . . . . . . . . . . . . . . . . . . . . 599 Jun Ding, Qiang Lu, Xianghua Chu

Development of a Remote Controlled Mobile Robot for Toy Application Using RF Module in PIC Microcontroller

Rionel Belen Caldo, Donabel D. Abuan, Elmer P. Dadios

Generalized Space Fourier Transform Method for the Analysis of Electrical Machines

Ankita Dwivedi, S.K. Singh, R.K. Srivastava

Product Attribute Analysis for Customer Involvement in Value Creation

Risdiyono

Influence of Gender of Customers on Service Quality

S. Valli Devasena

The Service Quality of Indonesia's Logistics Service Provider in Preparation for ASEAN Economic Community .

Mahendrawathi ER, Thananya Wasusri, Hanim Maria Astuti,

Anisah Herdiyanti 
Effects on Physical and Mechanical Properties of Thermochemical Treated Kenaf (Hibiscus Cannabinus) Fibres Composite Board . . . . . . . . . 657 Mohamad Nurul Azman Mohammad Taib, Mohd Ariff Jamaludin, Masitah Abu Kassim

Design Process Using Lean Six Sigma to Reduce the Receiving Discrepancy Report of ACE Logistics . 665 Jervie Bersamin, Roselyn Drio, Ariane Lanel Lacibal, Camille Manalastas, Sheily Mendoza, Ghil Michael Danico Orallo, Carl Timmothy Tan

A Study on Carbon Emission Effects of Foreign Direct Investment in Secondary Industry of Shandong Province . . . . . . . . . . . . . . . 675 Bin Xiong, Meng-jiao Wang

An Evaluation Performance of Log Periodic Dipole Antenna Based on the Parameter of Flux Density of the Solar Radio Burst Event . . . . 685 Z.S. Hamidi, N.N.M. Shariff

Attitude and Opinion of Bicycle-Helmet Signal . . . . . . . . . . . . . . . 693

Pattama Longani, Orawit Thinnukool, Anusorn Yodjaiphet

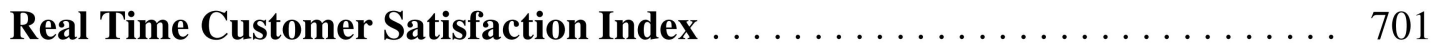

Afizan Azman, Luwe Cheng Wong, Mohd Fikri Azli, Siti Zainab,

Kirbana Jai Raman, Sumendra Yogarayan

FLC-Based Indoor Air Quality Assessment for ASHRAE Standard

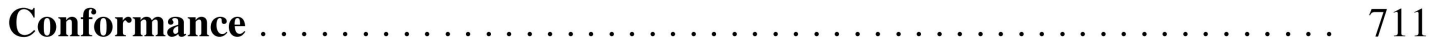
Rionel Belen Caldo

Artificial Intelligent System to Stop Bots from Playing Online Games . . . . . 719 Gagandeep Singh, Pooja Choudhary, Vikrant Sharma

Multi-lane Detection Based on Original Omni-Directional Images . . . . . . . 727 Chuanxiang Li, Bin Dai, Tao Wu

A Framework for Text Classification Using Intuitionistic Fuzzy Sets . . . . . 737 Peerasak Intarapaiboon

An Adaptive Incremental Fuzzy TSK Controller Combined

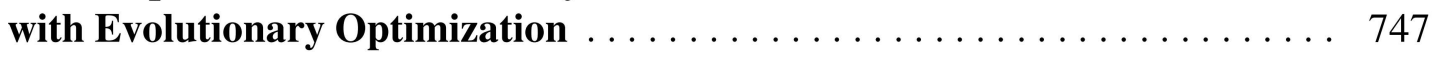
Niusha Shafiabady, Rajprasad K. Rajkumar, Dino Isa, J. Michael Menke, M.A. Nima Vakilian

Ground Grid Integrity Testing Using Matlab Fuzzy Logic Toolbox . . . . . . 759 Bryan M. Dimayuga, Kevin Martin E. Jaron, Alexander T. Montero, Mark Kenneth Z. Peros, Rionel Belen Caldo

Filtering as a Tool of Diversity in Ensemble of Classifiers . . . . . . . . . . . 767 Eva Volna, Martin Kotyrba, Vaclav Kocian 
Mining High Utility Patterns in Different Time Periods

Show-Jane Yen, Yue-Shi Lee

Content Based Image Retrieval Using Fuzzy Texton and Shearlet

Transform

Sudhakar Putheti, P.R. Krishna Prasad, Srinivasa Reddy Edara

Assessing Lean Implementation

Timo Schröders, Virgílio Cruz-Machado

Concealing of $\mathrm{Al}_{2}\left(\mathrm{SO}_{4}\right)_{3}$ Stain by Spray Coating Process

Chachsanun Srisoy, Suksan Prombanpong

Developing Interfaces Based on Services to the Cloud Manufacturing:

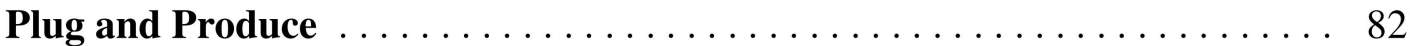

Eduardo Cardoso Moraes, Herman Augusto Lepikson,

Armando Walter Colombo

Optimization of Teflon Spraying Process for Non-stick Coating

Application................................ 833

Oraphan Poonkwan, Viboon Tangwarodomnukun, Suksan Prombanpong

Multidimensional Process Analytical System for Manufacturing

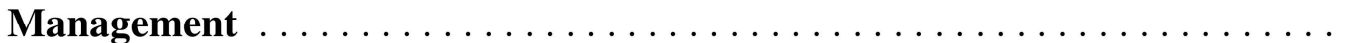

Poonphon Suesaowaluk

The Design of Machine Cluster for Loading and Unloading Slider in the Hard Disk Drive Manufacturing

Amarin Wongsetti, Suksan Prombanpong

A Study of Downloading Game Applications .

Long-Sheng Chen, Chen-Wei Yen

Explicating the Trends of China's Logistics Services for Electronic

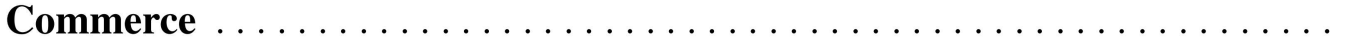

Mu-Chen Chen, Pei-Ju Wu, Wei-Hua Xiong

Measuring Customer Relationship Marketing Outcomes in the Greek

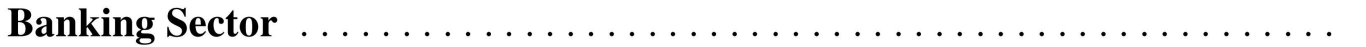

Ilias Santouridis, Melania Stoumbou

Analysis of Websites of Top Global Logistics Providers by a Trust Building Framework . . . . . . . . . . . . . . . . . . . . . . . . . . . . . .

Lachana Ramingwong, Sakgasit Ramingwong

An Empirical-Based Construction of the Multi-purpose Process

Reference Model for Hospital Supply Chain . . . . . . . . . . . . . . . . . . . 901

Wirachchaya Chanpuypetch, Duangpun Kritchanchai 
Smartphone Based Healthcare Platform and Challenges . . . . . . . . . . . . 913

Bofan Song, Bingwen Yu, Dan Zhu, Wei Jin, Ying Mu

Operating Rooms Decision Optimization Integrating Surgery Planning and Nurse Rostering . . . . . . . . . . . . . . . . . . . . . . . . . 919

Siyu Wang, Changyue Ma, Wei Xiang

Linking Hospital Supply Chain Processes and Performance to Identify Key Performance Indicator . . . . . . . . . . . . . . . . . . . . . . . . . 927

Tuangyot Supeekit, Tuanjai Somboonwiwat, Duangpun Kritchanchai

Kansei's Physiological Measurement in Small-Medium Sized Enterprises Using Profile of Mood States and Heart Rate . . . . . . . . . . . . . . . 939 Mirwan Ushada, Tsuyoshi Okayama, Nafis Khuriyati, Atris Suyantohadi

Investigation of Customer and Technical Requirements for Designing an Ergonomics Notebook Soft Case Using Quality Function Deployment (QFD) Approach . . . . . . . . . . . . . . . . . . . . . . . . . . . . . 949 Hilma Raimona Zadry, Defri Arif Irfansyah

Demographic Characteristics in Correlation with Household Electricity Use 959 Lusi Susanti, Prima Fithri, Karin Bestarina

Central Composite Design for the Experiments with Replicate Runs at Factorial and Axial Points Haeil Ahn

A Software Trustworthiness Measure Based on the Decompositions

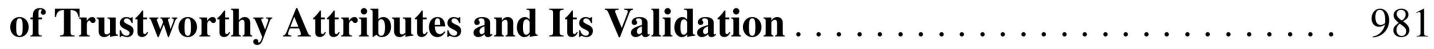
Hongwei Tao, Yixiang Chen, Jianmin Pang

Review Relationship TPM as Mediator between TQM and Business

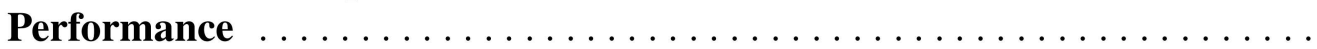
M.F. Ahmad, A.H. Nor Aziati, Abdul Talib Bon, Y. Ngadiman, Shiau Wei Chan

Theoretical Review of Critical Factors that Impact on Global Human Resource Practices: Case on Multinational Companies in Emerging Economies

Muhammad Mehmood Aslam, Syed Shaheer Hassan Rizvi, Asif Hameed

Ranking Measures for Sustaining Quality Excellence Practices: An Empirical Investigation . . . . . . . . . . . . . . . . . . . . . . . . . . . . . . . . 1009 Mehran Doulatabadi, Sha'ri Mohd Yusof

Software Reliability Analysis Considering the Fault Detection Trends for Big Data on Cloud Computing 1021 Yoshinobu Tamura, Shigeru Yamada 
XX Contents

Effect of Vibration Transmissibility on Fatigue Lifetime of Electronic

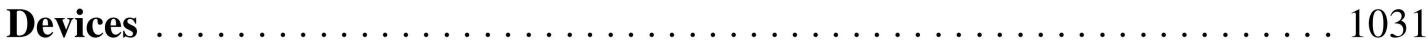

Liu Yang, Ying Chen, Zenghui Yuan, Liqun Chen

Reliability Importance of the Channels in Safety

Instrumented Systems . . . . . . . . . . . . . . . . . . . . . . . . . . 1041

Yiliu Liu, Mary Ann Lundteigen

Fatigue Damage Ratios for Heavy Vehicles Operating in the Southern

Part of Malaysian Peninsula . . . . . . . . . . . . . . . . . . . . . 1055

Osama Mahmoud Yassenn, Intan Rohani Endut, Mohamed Ahmed Hafez,

Siti Zaharah Ishak, Nurul Elma Kordi

Process Reliability Modeling Based on Nonlinear

Correlation Analysis . . . . . . . . . . . . . . . . . . . . . . . . . . . . 1065

Chuanliang Zhang, Wei Dai, Yu Zhao

Identification of Public Awareness in Preventive Maintenance

for Personal Automobile . . . . . . . . . . . . . . . . . . . . . . . . . . . . . . . . 1073

Y. Ngadiman, A.H. Nor Aziati, Abdul Talib Bon, M.F. Ahmad,

Raja Zuraidah Raja Mohd Rasi, Martin Yaw Swee Hock

A Novel Analysis of Clinical Data and Image Processing Algorithms

in Detection of Cervical Cancer . . . . . . . . . . . . . . . . . . . . . . . . . 1091

Abhishek Das, Avijit Kar, Debasis Bhattacharyya

Author Index 


\title{
Fuzzy Multi-objective Supplier Selection Problem: Possibilistic Programming Approach
}

\author{
Dicky Fatrias*, Ahmad Syafruddin Indrapriyatna, and Difana Meilani \\ Dept. of Industrial Engineering, Andalas University \\ Kampus limau Manis, Padang (25163), West Sumatera - INDONESIA \\ dicky@ft.unand.ac.id, ahmadsyafaft.unand.ac.id, \\ difana@ft.unand.ac.id
}

\begin{abstract}
In this paper, a multi-objective mathematical model is developed in fuzzy environment in which the vagueness in aspiration level of objectives and data imprecision regarding the selection criteria and related constraints are considered simultaneously as a source of fuzziness. In the model, such data imprecision is presented based on the estimation of its possibility distribution to better capture the uncertainty. Finally, a fuzzy solution methodology is constructed by the aid of weighted additive aggregation function to derive optimal solution. As preliminary investigation, we report that the proposed model is more flexible and convenient than the previous models whose imprecise parameters are treated as a given single estimated value.
\end{abstract}

\section{$1 \quad$ Introduction}

To remain competitive in a dynamically global market, the need to improve efficiency has prompted enterprises to seek opportunity to reduce costs while continuously improve their operation. Within the purchasing function, one of the key activities to achieve this goal is by selecting the appropriate supplier(s). In essential, supplier selection problem is a multi-criteria decision making within which criteria may be defined in quantitative and qualitative dimensions. Dickson [1] was the first to identify several criteria which are the most considered criteria in a practical supplier selection where quality, on-time delivery, performance history, warranty policy, and production facility/capacity of supplier were on the top five ranked in the list. A recent survey by Olson and $\mathrm{Wu}[2]$ study reported that cost, quality, and time response are major criteria that consistently appear for supplier selection.

The issue of considering uncertainty in supplier selection problem has received a great deal of concern in the field of supply chain management. This complexity in supplier selection stems from imprecise preferences of the decision maker (DM) regarding the aspiration level of decision objective and/or the imprecise nature of decision criteria and constraints. While the usefulness of stochastic approach has been documented, it is not always applicable in coding the information regarding the

\footnotetext{
* Corresponding author.
} 
imprecision of data and vagueness of goals. To avoid this drawback, the fuzzy approach is employed for modeling uncertain parameters. Moreover, it is frequently emphasized in the literature that fuzzy approach has had a great impact in preference modeling and multi-objective problem and has helped bring optimization techniques closer to the users' needs [3].

A number of studies have been devoted to examining supplier selection methods. Quantitative techniques have become increasingly applied recently. A comprehensive review of numerous quantitative techniques used for supplier selection has been done by [4].

This paper focuses on fuzzy multi-objective linear programming (fuzzy MOLP) to deal with supplier selection problem. Kumar et al. [5] developed a fuzzy multiobjective integer programming approach for supplier selection problem subject to constraints including buyer's demand and suppliers' capacity, and derived an optimal solution using max-min operator (Zimmermann's approach). To evaluate the performance of the model, they perform sensitivity analysis on the order allocation and objective function by changing the degree of uncertainty in supplier capacity. Amid et al. [6] solved fuzzy MOLP supplier selection problem by applying weighted additive aggregation function to facilitate an asymmetric fuzzy decision making technique. Since they found the performance of such a method is not adequate to support decision making process, $\alpha$-cut approach is then proposed to improve the resulted achievement level. Later on, Amid et al. [7] applied weighted max-min aggregation function in supplier selection problem and compared the performance of the proposed approach with max-min operator and weighted additive aggregation function. They found that the ratio of achievement level of objectives matches the ratio of the objectives weight. Yucel \& Guneri [8] proposed a new method of weights calculation in fuzzy MOLP supplier selection. Recent study by Arikan [9] developed a modified augmented max-min aggregation function that originally proposed by Lai dan hwang ([10],[11]) to solve fuzzy multi-objective supplier selection problem by considering a preference of the decision maker(s) (DMS) in determining the desired minimum achievement level of fuzzy objectives. The performance of the proposed approach is then is compared with the original augmented max-min and the weighted additive aggregation function in solving the test problem in Yucel \& Guneri [8]'s study. The study reported that while the modified augmented max-min outperforms the weighted additive in terms of the achievement level of fuzzy objectives, it shows insignificant improvement in performance when compared to the original augmented max-min.

Related to coding the imprecise data involved in supplier selection problem, all models in literatures assumed such imprecision is tackled by assigning a given single estimated value. In this paper, a solution methodology for multi-objective supplier selection problem is developed in fuzzy environment in which the data imprecision regarding the selection criteria and related constraints, and vagueness in aspiration level of objectives are considered simultaneously as a source of fuzziness. Unlike the previous models, data imprecision is generated based on its possibility distribution in order to better capture the uncertainty. A fuzzy mathematical model is then developed by the aid of weighted additive aggregation function to derive a set of optimal solution. 


\section{Fuzzy Multi-objective Programming Methodology}

\subsection{Fuzzy Multi-objective Preliminary Formulation}

A fuzzy formulation of the multi-objective linear programming (MOLP) with imprecise coefficient and fuzzy aspiration level of objectives can be stated as

$$
\begin{gathered}
\min Z_{k}=\sum_{i=1}^{n} \tilde{c}_{k i} x_{i} \leq \sim Z_{k}^{0}, \quad k=1,2, \ldots, p \\
\max \tilde{Z}_{l}=\sum_{i=1}^{n} \tilde{c}_{l i} x_{i} \geq \sim Z_{l}^{0}, \quad l=p+1, p+2, \ldots, q
\end{gathered}
$$

subject to:

$$
\begin{gathered}
g_{s}=\sum_{i=1}^{n} a_{s i} x_{i} \leq \tilde{b}_{s}, s=h+1, h+2, \ldots, m \\
x_{i} \geq 0, i=1,2, \ldots, n
\end{gathered}
$$

The symbol $\leq \sim$ and $\geq \sim$ denotes the fuzzified version of $\leq$ and $\geq$, respectively. The notation of $\tilde{c}_{k i}$ and $\tilde{c}_{l i}$ are imprecise coefficients, and $Z_{k}^{0}$ and $Z_{l}^{0}$ are the aspiration levels that the DM wants to reach. The above fuzzy mathematical formulation is characterized by linear membership function whose value changes between 0 and 1 . The linear membership function for fuzzy objectives are given as [12]:

$$
\begin{aligned}
& \mu_{Z k}=\frac{Z_{k}^{\text {max }}-Z_{k}(x)}{z_{k}^{\text {max }}-Z_{k}^{\text {min }}} \\
& \mu_{Z l}=\frac{Z_{l}(x)-Z_{l}^{\text {min }}}{z_{l}^{\text {max }}-z_{l}^{\text {min }}}
\end{aligned}
$$

Here $Z_{k}^{\max }, Z_{l}^{\max }, Z_{k}^{\min }$, and $Z_{l}^{\min }$ means the maximum value and the minimum value of $Z_{k}$ and $Z_{l}$, respectively. They are obtained by solving a single objective optimization problem respectively under each objective function.

\subsection{Modeling Imprecise Parameter using Possibilistic Programming}

In possibilistic programming, each imprecise data (ill-known parameter) has its possibility distribution which represents the possibility degree of occurrence of possible value for each imprecise parameter. A several number of distributions exist in literature such as triangular, trapezoidal and so on. Among them, triangular are the most commonly used distributions in solving possibilistic programming problems [2]. Using triangular distribution, a possibilistic programing with imprecise parameter $\sum_{i=1}^{n} \tilde{c}_{i} x_{i}$ is redefined as

$$
\max / \min \sum_{i=1}^{n}\left(c_{i}^{p}, c_{i}^{m}, c_{i}^{o}\right) x_{i}
$$

where $c^{p}, c^{m}$ and $c^{o}$ are the most pessimistic, the most likely and the most optimistic value of imprecise parameter, respectively. These values are usually estimated by the DMs based on available data as well as their knowledge. 
Jimenez et al., [13] proposed a method to define a single crisp representation of $c^{p}, c^{m}$ and $c^{o}$ based on the concept of expected interval and expected value of fuzzy numbers. It has been proven that this method is computationally efficient to solve such problems as it can preserve its linearity and do not increase the number of objective functions and inequality constraints [14].

The crisp representation of imprecise parameters of fuzzy MOLP problem in Eq. (1) - (4) can be formulated as follows [13]:

$$
\begin{gathered}
\tilde{Z}_{k}=\sum_{i=1}^{n}\left(\frac{c_{k i}^{p e s}+2 c_{k i}^{m o s}+c_{k i}^{o p t}}{4}\right) x_{i} \leq \sim Z_{k}^{0} \\
\tilde{Z}_{l}=\sum_{i=1}^{n}\left(\frac{c_{l i}^{p e s}+2 c_{l i}^{m o s}+c_{l i}^{o p t}}{4}\right) x_{i} \geq \sim Z_{l}^{0}
\end{gathered}
$$

subject to:

$$
\begin{gathered}
g_{s}=\sum_{i=1}^{n} a_{s i} x_{i} \leq\left[\alpha\left(\frac{b_{s}^{p e s}+b_{s}^{m o s}}{2}\right)+(1-\alpha)\left(\frac{b_{s}^{\text {mos }}+b_{s}^{o p t}}{2}\right)\right] \\
x_{i} \geq 0, \quad i=1,2, \ldots, n
\end{gathered}
$$

where $\alpha$ is a minimum acceptable feasibility degree of decision vector which can be varied according to subjective preference of the DM.

\subsection{Fuzzy Aggregation Function}

A fuzzy aggregation function is typically used to solve fuzzy multi-objective programming problem by converting such problem into single objective formulation. Solving the aggregation function results in the efficient solution in terms of the satisfaction degree of each objective from which the DMs choose the final decision based on his/her preference (relative importance among objectives). Tiwari et al [15] proposed weighted additive aggregation function which had been widely used in vectorobjective optimization problems. The function is stated as follow:

$$
\operatorname{Max} \sum_{k} \omega_{k} \lambda_{k}
$$

subject to:

$$
\begin{gathered}
\lambda_{k} \leq \mu_{Z k} \\
\lambda_{k}, \mu_{Z k}, \omega_{k} \in[0,1] \\
\sum_{k} \omega_{k}=1
\end{gathered}
$$

where $\lambda_{k}$ denote the satisfaction degree of $k$-th objective (individual satisfaction degree of each objective). 


\section{Fuzzy Multi-objective Supplier Selection Problem}

\subsection{Model Formulation}

A typical linear model for multi-objective supplier selection problems is presented as follows [7]:

\section{$\underline{\text { Index set }}$}

$i$ index for suppliers, for all $\mathrm{i}=1,2, \ldots, \mathrm{n}$

\section{Decision variable}

$x_{i} \quad$ The number of units purchased from the $i$-th supplier

\section{Parameters}

$D$ Aggregate demand of the item over a fixed planning period.

$n \quad$ Number of suppliers competing for selection

$p_{i} \quad$ Unit net purchase cost from supplier $i$

$f_{i} \quad$ percentage of product quality of the supplier $i$

$s_{i} \quad$ Service performance of the supplier $i$

$C_{i} \quad$ Capacity of $i$-th supplier

Following the formulation of the fuzzy MOLP problem in Eqs. (1)-(4), the crisp representation of the above problem using Eqs. (8)-(11) can be stated as follows:

$$
\begin{aligned}
& \operatorname{Min} \tilde{Z}_{1}=\sum_{i=1}^{n}\left(\frac{p_{i}^{\text {pes }}+2 p_{i}^{\text {mos }}+p_{i}^{o p t}}{4}\right) x_{i} \leq \sim Z_{1}^{0} \\
& \operatorname{Max} \tilde{Z}_{2}=\sum_{i=1}^{n}\left(\frac{f_{i}^{\text {pes }}+2 f_{i}^{\text {mos }}+f_{i}^{o p t}}{4}\right) x_{i} \geq \sim Z_{2}^{0} \\
& \operatorname{Min} \tilde{Z}_{3}=\sum_{i=1}^{n}\left(\frac{s_{i}^{\text {pes }}+2 s_{i}^{\text {mos }}+s_{i}^{\text {opt }}}{4}\right) x_{i} \geq \sim Z_{3}^{0}
\end{aligned}
$$

subject to:

$$
\begin{gathered}
\sum_{i=1}^{n} x_{i} \geq\left[\alpha\left(\frac{D^{m o s}+D^{o p t}}{2}\right)+(1-\alpha)\left(\frac{D^{p e s}+D^{m o s}}{2}\right)\right] \\
x_{i} \leq\left[\alpha\left(\frac{C_{i}^{\text {pes }}+C_{i}^{\text {most }}}{2}\right)+(1-\alpha)\left(\frac{C_{i}^{\text {most }}+C_{i}^{o p t}}{2}\right)\right] \\
x_{i} \geq 0
\end{gathered}
$$

Eq. (13) minimizes the net cost for ordering product to satisfy demand. Eq. (14) maximizes the quality requirement of each supplier. Eq. (15) maximized the service performance of each supplier. Eq. (16) ensures that order quantity assigned to suppliers must satisfy the total demand. Eq. (17) guarantees that the order quantity assigned 
to each supplier will not exceed supplier capacity limit. Eq. (18) is non-negativity constraint.

\subsection{Step-by-step Solution Methodology}

We propose solution methodology to facilitate the decision-making process in solving multi-objective supplier selection problem with imprecise parameters and fuzzy aspiration level of objectives. The steps are summarized as follows:

Step 1: Construct the fuzzy MOLP supplier selection problem with imprecise parameters and fuzzy aspiration level according to defined criteria and constraints.

Step 2: Transform the model into an equivalent crisp representation of multiobjective model by converting all the imprecise parameters (i.e., criteria data, aggregate demand and capacity of each supplier).

Step 3: Determine the minimum acceptable feasibility degree ( $\alpha$-level) and then construct membership function for each fuzzy objective function using lower and upper bounds of each objective for the desired $\alpha$-level.

Step 4: Specify the weight of each objective and solve the model using weighted additive aggregation function.

Step 5: Present the optimal solution set according to predetermined $\alpha$ value. When the DM desires to change his/her preference in respond to uncertainty and/or the weight of each objective, change the corresponding values and repeat the procedure from step 3 .

Table 1. Supplier quantitative information

\begin{tabular}{|c|c|c|c|c|}
\hline Supplier $n$ & Cost $(\$)$ & Quality (\%) & Service $(\%)$ & Capacity (unit) \\
\hline 1 & $\{11,13,15.5\}$ & $\{65,80,95\}$ & $\{70,85,90\}$ & $\{550,700,800\}$ \\
\hline 2 & $\{10,11.5,13\}$ & $\{60,70,80\}$ & $\{60,75,85\}$ & $\{400,600,700\}$ \\
\hline 3 & $\{13,15,16.5\}$ & $\{70,80,99\}$ & $\{70,80,95\}$ & $\{300,500,650\}$ \\
\hline
\end{tabular}

\section{$4 \quad$ Numerical Example}

The following example is based on Amid, Ghodsypour and O'Brien [7]' s study.

Consider one company which considers three candidates of supplier for ordering plan of one product. Management wants to improve the efficiency of the purchasing process by evaluating their suppliers using three criteria which are net price, quality and service. Based on this description the objectives are developed as minimizing net cost of purchasing a product to the suppliers, maximizing quality rate and maximizing service performance of suppliers.

To show the effectiveness of the proposed solution methodology, the original criteria data from Amid, Ghodsypour and O'Brien [7]' s study are presented as imprecise parameters, following the assumption that the data is imprecise. As a result, rather than estimates a single value for each of the data, the DM determines the estimation 
of its possibility distribution by deciding three prominent values (i.e., the most likely, the most pessimistic and the most optimistic values) based on their current available information and knowledge. The constraints regarding the total demand and the capacity of each supplier are also considered imprecise in nature. As a result, the estimated values of their cost, quality and delivery performance, and associated constraints of suppliers are presented in Table 1.

Several results with different $\alpha$-level (i.e. $\alpha=0.0,0.2,0.4,0.6,0.8,1.0$ ) are provided in performance testing and for each $\alpha$-level alternative solution sets are generated by the aid of the weighted additive aggregation function. The weight of cost, quality and service are given as $\omega_{1}=0.63, \omega_{1}=0.21$ and $\omega_{1}=0.16$ [16]. Due to space limitation, the detail formulations according to the step-by-step procedures of methodology are not presented in the paper.

Table 2. Different sets of optimal solution

\begin{tabular}{llllll}
\hline Item & Amid et al. & & \multicolumn{3}{c}{ Proposed model } \\
& $(2011)$ & $\alpha=0.0$ & $\alpha=0.2$ & $\alpha=0.4$ & $\alpha=0.6$ \\
\hline$Z_{1}$ & 12000 & 10756 & 11264 & 11773 & 12281 \\
$Z_{2}$ & 740 & 655 & 686 & 717 & 748 \\
$Z_{3}$ & 807 & 686 & 717 & 749 & 780 \\
$x_{1}, x_{2}, x_{3}$ & $400,600,0$ & $250,650,0$ & $315,650,0$ & $380,590,0$ & $445,560,0$ \\
$\mu_{z 1}$ & 1.000 & 1.000 & 1.000 & 1.000 & 1.000 \\
$\mu_{z 2}$ & 0.000 & 0.000 & 0.000 & 0.000 & 0.000 \\
$\mu_{z 3}$ & 0.300 & 0.004 & 0.005 & 0.007 & 0.010 \\
\hline
\end{tabular}

According to the result provided in Table 2 the value of all objective functions increases when the minimum acceptable feasibility degree ( $\boldsymbol{\alpha}$-level) is increased. In other words, when the DM decided to response to uncertainty with a higher confidence level, all objective functions are also augmented. This could be due to the need to order more quantity of product (in total) in higher $\boldsymbol{\alpha}$-level.

It is also revealed that the second and third objective (quality and service) are critical objectives as the corresponding achievement level is always in the worst possible value in any $\boldsymbol{\alpha}$-levels. This implies that the model tends to sacrifice the performance of these objectives because it is at less of cost decreasing the performance of these objectives rather than decreasing the performance of the first objective (net price). This phenomenon is directly influenced by the fact that the first objectives is the most important ones whose assigned weight is the highest, according to the DM's preference $\left(\omega_{1}>\omega_{2}>\omega_{3}\right)$.

As it was mentioned in Section 3.2, the value of minimum acceptable feasibility degree ( $\boldsymbol{\alpha}$-level) and the weight of the objectives can also be varied according to the DM preferences (other than illustrated above), yielding some alternative solution sets from which the DM select the most preferred solution. Hence, besides providing a broader decision spectrum, the proposed model is also more flexible and convenient than the previous models whose imprecise parameters are treated as a single estimated value. 


\section{Conclusion}

In this paper, a solution methodology for multi-objective supplier selection problem is developed by simultaneously considering vagueness in aspiration level of objectives as well as the imprecision nature of to criteria data and related constraints. To better capture the uncertainty embedded in selection process, the model facilitates a judgment of the DM to estimate of the possibility distribution of each criterion and constraints by deciding three prominent values based on their current available information and knowledge.

According to the preliminary investigation, the main feature of the proposed model is the ability to yield different solution set with adjusted ordering decision based on a different minimum acceptable feasibility degree $(\boldsymbol{\alpha}$-level) in order to facilitate the DM to set his/her confident level in response to the uncertainty in imprecise criteria data and related constraint (i.e., demand and capacity) in supplier selection problem. Another interesting feature were also mentioned regarding the flexibility of the model compared to the recent models whose imprecise parameters are treated as a single estimated value.

Acknowledgments. This work has been funded by Directorate General of Higher Education, INDONESIA, under a program of Fundamental Research Grant 2015.

\section{References}

1. Dickson, G.W.: An analysis of vendor selection: system and decisions. Journal of Purchasing 1, 5-17 (1966)

2. Olson, D.L., Wu, D.: Simulation of fuzzy grey relationships. European Journal of Operational Research 175(1), 111-120 (2006)

3. Selim, H., Araz, C., Ozkarahan, I.: Collaborative production-distribution planning in supply chain: A fuzzy goal programming approach. Transportation Research Part E 44, 396-419 (2008)

4. Weber, C.A., Current, J.R., Benton, W.C.: Vendor selection criteria and methods. European Journal of Operation Research 50, 2-18 (1991)

5. Kumar, M., Vrat, P., Shankar, R.: A fuzzy programming approach for vendor selection problem in a supply chain. Int. J. Production Economics 101, 273-285 (2006)

6. Amid, A., Ghodsypour, S.H., O’Brien, C.: Fuzzy multiobjective linear model for supplier selection in a supply chain. Int. J. Production Economics 104, 394-407 (2006)

7. Amid, A., Ghodsypour, S.H., O'Brien, C.: A weighted max-min model for fuzzy multiobjective supplier selection in a supply chain. Int. J. Production Economics 131, 139-145 (2011)

8. Yucel, A., Guneri, A.F.: A weighted additive fuzzy programming approach for multicriteria supplier selection. Expert Systems with Applications 38, 6281-6286 (2011)

9. Arikan, F.: Fuzzy Solutio approach for fuzzy multi-objective supplier selection problem. Expert Systems with Applications 40, 947-952 (2013)

10. Lai, Y.J., Hwang, C.L.: Possibilistic linear programming for managing interest rate risk. Fuzzy Sets and Systems 49, 121-133 (1993) 
11. Lai, Y.J., Hwang, C.L.: Fuzzy multiple objective decision making-methods and applications. Springer, Germany (1996)

12. Zimmermann, H.J.: Fuzzy programming and linear programming with several objective functions. Fuzzy sets and systems 1, 45-46 (1978)

13. Jimenez, M., Arenas, M., Bilbao, A., Rodriguez, M.V.: Linear programming with fuzzy parameters: An interactive method resolution. Eur. J. Oper. Res. 177, 1599-1609 (2007)

14. Pishvaee, S.M., Razmi, J.: Environmental supply chain network design using multiobjective fuzzy mathematical programming. Applied Mathematical Modelling 36, 3433-3446 (2012)

15. Tiwari, R.N., Dharmar, S., Rao, J.R.: Fuzzy goal programming an additive model. Fuzzy Sets and Systems 24, 27-34 (1987)

16. Ghodsypour, S.H., O'Brien, C.: A decision support system for supplier selection using an integrated analytical hierarchy process and linear programming. International Journal of Production Economics 56 57, 199-212 (1998) 